\title{
Microduplications upstream of MSX2 are associated with a phenocopy of cleidocranial dysplasia
}

\author{
Claus Eric Ott, ${ }^{1}$ Hendrikje Hein, ${ }^{2,3}$ Silke Lohan, ${ }^{1,2}$ Jeannette Hoogeboom, ${ }^{4}$ \\ Nicola Foulds, ${ }^{5}$ Johannes Grünhagen, ${ }^{1}$ Sigmar Stricker, ${ }^{1,2}$ Pablo Villavicencio-Lorini, ${ }^{1,2}$ \\ Eva Klopocki, ${ }^{1,2}$ Stefan Mundlos ${ }^{1,2,3}$
}

\begin{abstract}
- Additional materials are published online only. To view these files please visit the journal online (http://jmg.bmj. com/content/49/7.toc).
\end{abstract}

${ }^{1}$ Institute for Medical Genetics and Human Genetics,

Charité-Universitätsmedizin Berlin, Berlin, Germany ${ }^{2}$ Research Group Development and Disease, Max-Planck Institute for Molecular Genetics, Berlin, Germany

${ }^{3}$ Berlin-Brandenburg Center for Regenerative Therapies (BCRT), Berlin, Germany

${ }^{4}$ Department of Clinical Genetics, Erasmus MC University Medical Center, Rotterdam, The Netherlands ${ }^{5}$ Department of Human Genetics and Genomic Medicine,

University Hospital of Southampton NHS Foundation Trust, Faculty of Medicine, University of Southampton, Hampshire, UK

\section{Correspondence to} Dr rer. nat. Eva Klopocki, Institute for Medical Genetics and Human Genetics, Charité-Universitätsmedizin Berlin, Augustenburger Platz 1 , 13353 Berlin, Germany; eva.klopocki@charite.de

Received 9 March 2012 Revised 17 May 2012 Accepted 29 May 2012 Published Online First 20 June 2012

\begin{abstract}
Background Cleidocranial dysplasia (CCD) is an autosomal dominant skeletal disorder characterised by hypoplastic or absent clavicles, increased head circumference, large fontanels, dental anomalies and short stature. Although CCD is usually caused by mutations leading to haploinsufficiency of RUNX2, the underlying genetic cause remains unresolved in about $25 \%$ of cases.
\end{abstract}

Methods Array comparative genomic hybridisation was performed to detect copy number variations (CNVs). Identified CNVs were characterised by quantitative PCR and sequencing analyses. The effect of candidate genes on mineralisation was evaluated using viral overexpression in chicken cells

Results In 2 out of 16 cases, the authors identified microduplications upstream of MSX2 on chromosome $5 q 35.2$. One of the unrelated affected individuals presented with a phenocopy of CCD. In addition to a classical CCD phenotype, the other subject had a complex synpolydactyly of the hands and postaxial polydactyly of the feet which have so far never been reported in association with CCD or CNVs on 5q35.2. The duplications overlap in an $\sim 219 \mathrm{~kb}$ region that contains several highly conserved non-coding elements which are likely to be involved in MSX2 gene regulation. Functional analyses demonstrated that the inhibitory effect of Msx2 overexpression on mineralisation cannot be ameliorated by forced Runx2 expression.

Conclusions These results indicate that CNVs in noncoding regions can cause developmental defects, and that the resulting phenotype can be distinct from those caused by point mutations within the corresponding gene. Taken together, these findings reveal an additional mechanism for the pathogenesis of CCD, particularly with regard to the regulation of MSX2.

Cleidocranial dysplasia (CCD, MIM 119600) is an autosomal dominant skeletal disorder that affects bones derived from endochondral as well as intramembranous ossification such as the cranium, the clavicles and, to a lesser degree, long bones. Characteristic features of the skull are enlarged fontanelles with delayed closure, Wormian bones, frontal bossing and mid-face hypoplasia. The most prominent clinical feature is narrow, sloping shoulders that can be apposed at the midline due to aplastic or hypoplastic clavicles. Further features include various dental anomalies, including supernumerary teeth and delayed eruption of permanent teeth, short stature and hand abnormalities, as well as other skeletal changes. ${ }^{1}$

CCD is mainly caused by loss-of-function mutations in runt-related transcription factor 2 (RUNX2, MIM 600211), also known as core-binding factor A1. ${ }^{2}$ The osteoblast-specific transcription factor RUNX2 is a member of the runt-domain gene family and promotes the differentiation of mesenchymal cells into osteoblasts. ${ }^{3}{ }^{4}$ Point mutations in RUNX2 can be detected in about $60 \%-70 \%$ of all affected individuals with CCD, and heterozygous deletions can be identified in about $10 \%{ }^{2}{ }^{5}$

Some other hereditary skeletal disorders resemble CCD to a certain degree, and at least some of these disorders result from mutations in genes that affect the action of RUNX2 on its target genes. Abnormalities in core-binding factor $\beta$ (CBFB, MIM 121360), which interacts with RUNX2, cause skeletal anomalies such as large fontanelles, hypoplasia of the distal phalanges and delayed ossification. ${ }^{67}$ Parietal foramina with cleidocranial dysplasia (PFMCCD, MIM 168550) is caused by loss-of-function mutations of Drosophila muscle segment homeobox gene homologue 2 (MSX2, MIM 123101) and is therefore another entity aetiologically and phenotypically distinct from RUNX2-related CCD. Characteristic clinical features of PFMCCD are mild clavicular hypoplasia, craniofacial abnormalities such as a broad forehead and central bossing, and symmetrical oval defects of the parietal bones which are termed parietal foramina. ${ }^{8}$ Parietal foramina can occur in combination with clavicular hypoplasia in case of $M S X 2$ mutations or isolated due to mutations in MSX2 or aristaless-like 4 (ALX4, MIM 605420). ${ }^{9}{ }^{10}$

Genome-wide screening methods such as microarray-based comparative genomic hybridisation (array $\mathrm{CGH}$ ) are a valuable tool to detect submicroscopic copy number variations (CNVs). To further investigate the underlying genetic cause of $\mathrm{CCD}$, we performed array CGH $(244 \mathrm{~K}$ or $1 \mathrm{M}$ oligonucleotide array, Agilent Technologies, Santa Clara, California, USA) in 16 individuals in whom mutations and CNVs in RUNX2, CBFB and MSX2 had been excluded. Data analysis was carried out as described previously. ${ }^{11}$ Using this approach, we detected microduplications of different sizes on chromosome 5q35.2 in two unrelated affected individuals (Supplementary figure S1, Supplementary figure S2). 
Affected individual 1 (P1) presented with typical signs of CCD. As shown in figure 1A, he was able to appose his shoulders at the midline due to a complete absence of both clavicles (figure 1B). At the age of 4 years, he showed a persistent anterior fontanelle (figure 1C) but no signs of parietal foramina or other abnormalities of the skull (figure 1D). X-rays of the hands (figure 1E) and the pelvis (figure $1 \mathrm{~F}$ ) revealed signs of delayed bone age. The anlagen of some deciduous teeth were missing (figure 1G). Cardiac arrhythmia had been repeatedly found during cardiological examination including Holter ECG monitoring, but no structural heart malformation was detectable by ultrasound.

Array CGH identified an $\sim 1.7 \mathrm{Mb}$ duplication upstream of MSX2 in this individual (Supplementary figure S1; Decipher BER264221). Quantitative PCR (qPCR) was used to refine the breakpoint intervals and to confirm de novo occurrence of the duplication (Supplementary figure S3A). The centromeric breakpoint was localised within an $\sim 0.7 \mathrm{~kb}$ interval (chr5:172,411,905-172,412,552) flanked by qPCR amplicons A3 and $\mathrm{A} 4$, and the telomeric breakpoint within an $\sim 2.1 \mathrm{~kb}$ interval (chr5:174,066,198-174,068,279) flanked by amplicons A9 and A10 (figure 2A; genomic positions are given according to hg19). Analysis by PCR with primers A9-forward and A4-reverse (Supplementary table S1) on genomic DNA level allowed amplification and sequencing analysis of a junction fragment which contained a homology of $37 \mathrm{bp}$ beginning at the telomeric site on position 174,067,202 and at the centromeric site on position 172,412,091 (Supplementary figure S4A). Both breakpoints were localised within AluY elements. These data are consistent with unequal homologous recombination as a conceivable mechanism leading to the $\sim 1655 \mathrm{~kb}$ microduplication oriented in direct tandem and localised $\sim 69 \mathrm{~kb}$ upstream of $M S X 2$ (figure $2 \mathrm{~B}$ ).

Affected individual 2 (P2) presented with typical features of CCD. Both clavicles were absent (figure $1 \mathrm{H}$ ), and at the age of
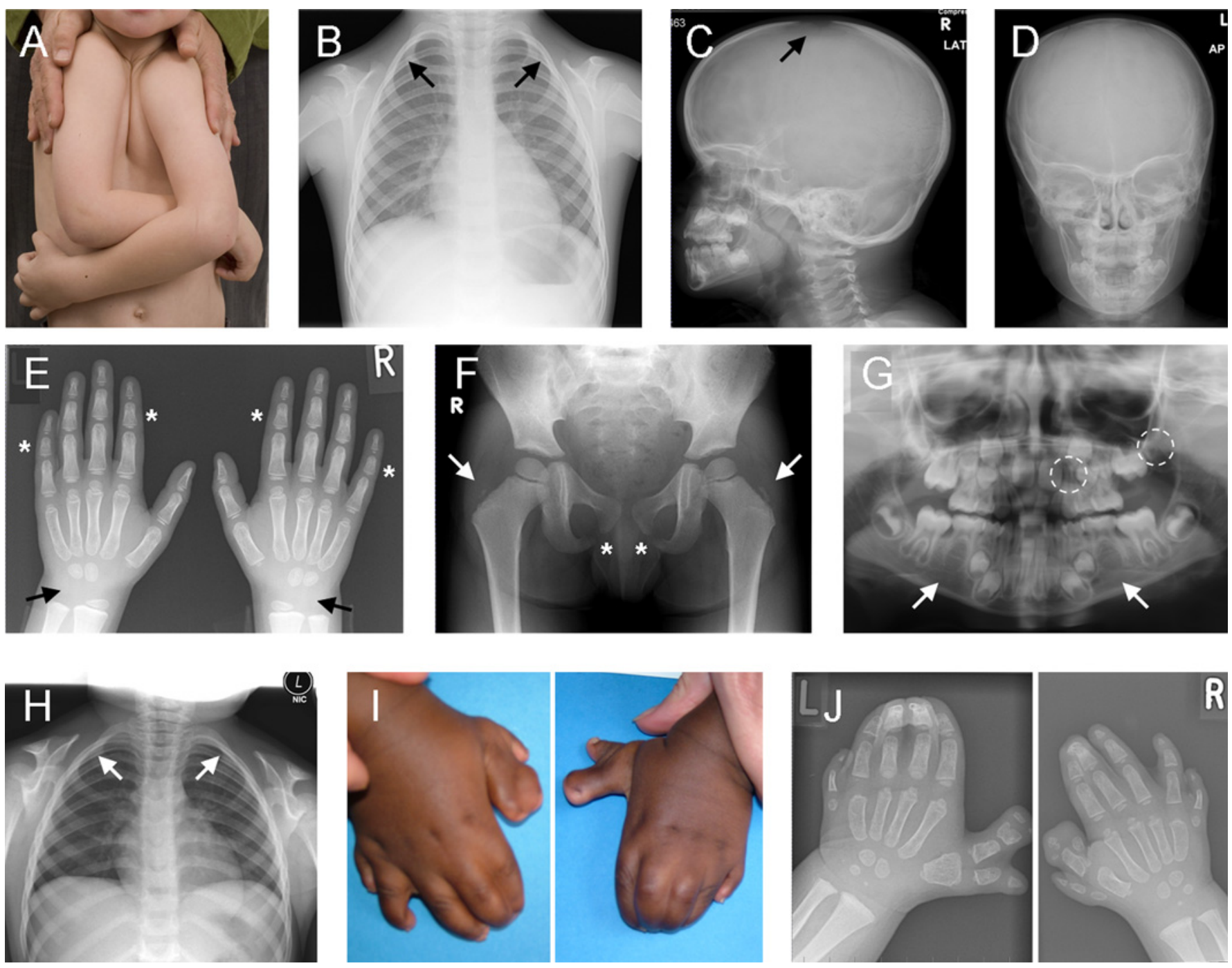

Figure 1 Clinical phenotypes associated with microduplications at the MSX2 locus on 5q35.2. (A-G) Clinical phenotype of P1. (A) Hypermobility of the shoulders. (B) X-rays of the thorax showing absent clavicles on both sides (arrows). (C) The skull defect at the age of 4 years and 3 months is marked by an arrow (lateral view). (D) AP picture. There are no signs of parietal foramina or craniosynostosis. (E) X-rays of the hands at the age of 4 years and 6 months. The middle phalanges of digit II and V appear slightly shortened (asterisks). Os triquetrum and os lunatum are not visible in both wrists (arrows) which correspond to a carpal age of 2 years. (F) X-rays of the pelvis. On both sides, the synchondrosis ischiopubica is still open (asterisks) and the ossification centres of trochanter major are relatively small (arrows). (G) Orthopantogram at the age of 7 years and 11 months. The anlagen of the deciduous teeth 22 and 27 (circles) as well as 35 and 45 (arrows) are missing. $\mathrm{H}-\mathrm{J}$ Clinical phenotype of P2. (H) X-rays of the thorax showing absent clavicles on both sides (arrows). (I) Limb phenotype with synpolydactyly of both hands and (J) corresponding $\mathrm{X}$-rays. 
Figure 2 Schematic overview of microduplications at the MSX2 locus on 5q35.2. The duplicated sequences observed in the affected individuals with CCD are shown as coloured rectangles (green, duplication $\mathrm{P} 1$; orange, proximal duplicon $\mathrm{P} 2$; yellow, distal duplicon P2). Coloured boxes in $\mathrm{B}$ and $\mathrm{C}$ correspond to the junction fragments shown in Supplementary figure S4. (A) The approximate positions of quantitative PCR amplicons used to refine the breakpoint intervals are indicated $(A 1-A 10)$. On top, the proximal overlapping duplicated sequence (region 1) is enlarged showing the genes within this interval. The conservation of the distal overlapping duplicated sequence (region 2) is depicted in the ECR browser plot. Note that there are no RefSeq genes in this interval. The sequence upstream of the mouse homologue Msx2 is located on different chromosomes as indicated by the grey bars. For clarity, the four genes between region 1 and region 2 duplicated only in P1 (cf, Supplementary figure $S 1$ ) are not illustrated. (B) Direct tandem orientation of the microduplication in P1. (C) As heterozygous SNPs could be identified both at the centromeric end of the proximal duplication and at the telomeric end of the distal duplication, there remain two variants (variant $A$ or variant $B$ ) for the arrangement of the duplicons in P2. The genuine position of the duplicons on the normal allele is shown at the bottom. (B and $C) A 9 F$, $\mathrm{A} 4 \mathrm{R}, \mathrm{A} 5 \mathrm{bF}, \mathrm{A} 8 \mathrm{R}, \mathrm{A} 9 \mathrm{bF}$ and $\mathrm{A} 2 \mathrm{bR}$ refer to the PCR primers used to amplify the different junction fragments.

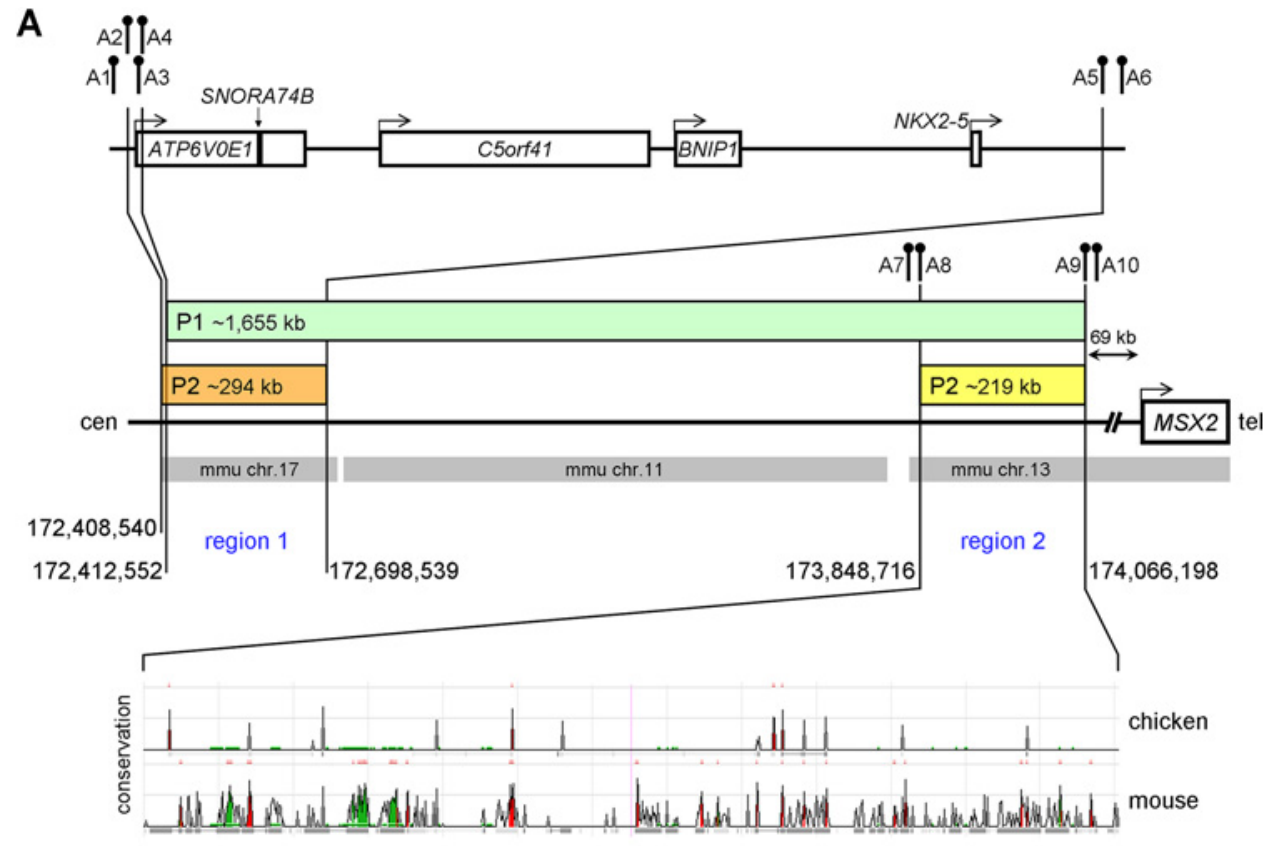

B
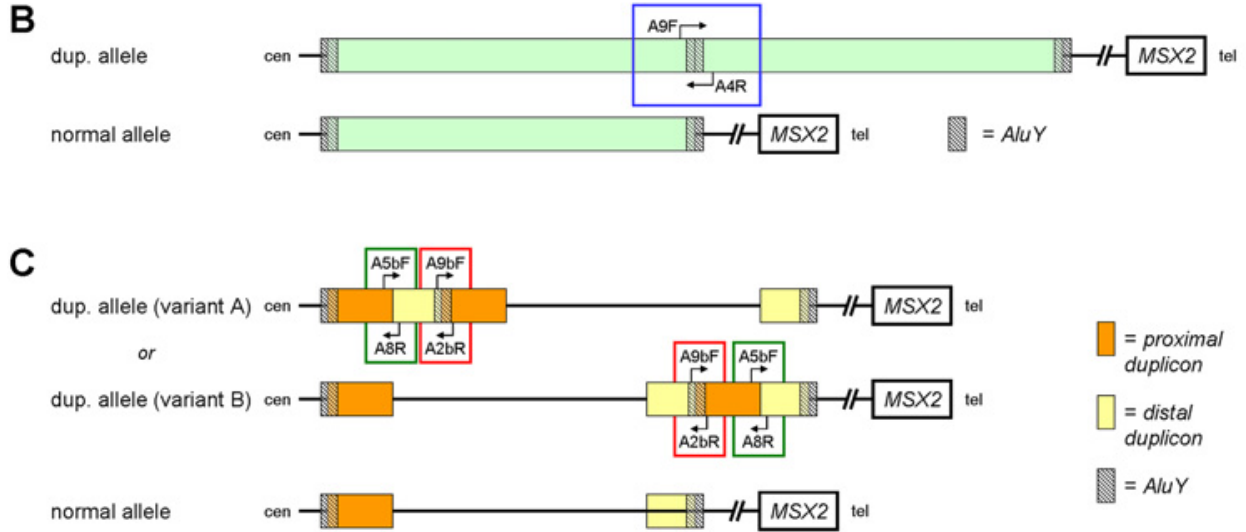

3 years the anterior fontanelle was still open. In addition to classical features of CCD, she presented with a complex synpolydactyly of the hands (figure 1I,J) and postaxial polydactyly of the feet which have so far never been described in patients with CCD or in association with CNVs on 5q35.2. By sequencing analysis, no mutation was identified in genes known to be associated with limb malformations such as GLI3 (MIM 165240), ROR2 (MIM 602337), HOXD13 (MIM 142989), TWIST1 (MIM 601622), ALX4 (MIM 605420) and EFNB1 (MIM 300035). Array CGH identified an $\sim 0.3 \mathrm{Mb}$ duplication $\sim 1.5 \mathrm{Mb}$ upstream of MSX2 and, further telomeric, a second $\sim 0.2 \mathrm{Mb}$ duplicated region $\sim 0.1 \mathrm{Mb}$ upstream of MSX2 (Supplementary figure S2; Decipher BER264214). qPCRs with amplicons indicated in figure $2 \mathrm{~A}$ confirmed both duplications. Analysis of the parents revealed normal results, thus, confirming de novo occurrence of both duplicated sequences (Supplementary figure S3B).

The four breakpoint intervals were narrowed down by qPCR. Further analysis by PCR on genomic DNA level using different primer combinations both for inverted or tandem orientation of the duplicated sequences in region 1 and region 2 allowed no amplification of a junction fragment, whereas PCR with primers A9b-forward and A2b-reverse and with primers A5b-forward and A8-reverse (Supplementary table S1) allowed the identification and sequencing analysis of two different junction fragments. Junction 1 connects the telomeric end of the distal duplication $(\mathrm{A} 9 \rightarrow \mathrm{A} 10)$ with the centromeric end of the proximal duplication (A1 $\leftarrow$ A2) and contains a homology of $21 \mathrm{bp}$ beginning at the telomeric site on position 174,067,232 and at the centromeric site on position 172,406,206 (Supplementary figure S4B). The telomeric breakpoint in junction 1 is almost identical with the telomeric breakpoint identified in P1. Similar to the situation in $\mathrm{P} 1$, unequal homologous recombination between Alu repeats would be a conceivable mechanism.

In junction 2 (Supplementary figure $\mathrm{S} 4 \mathrm{C}$ ), the proximal duplicated sequence ends at position $172,700,622(\mathrm{~A} 5 \rightarrow \mathrm{A} 6$ ) and the distal duplicated sequence begins at position $173,847,989$ (A7 $\leftarrow$ A8). In between there is a short insertion of eight nucleotides. These findings can best be explained by break-induced non-homologous DNA end joining as underlying mechanism. Two possibilities for the complex genomic rearrangement in P2 remain to be considered with either one copy of the $\sim 219 \mathrm{~kb}$ distal duplicon localised in direct orientation in between two copies of the $\sim 294 \mathrm{~kb}$ proximal duplicon or vice versa (figure 2C). Unfortunately, it was not possible to finally clarify the arrangement of the duplicons by FISH analysis. Additional 
information on the complex rearrangement observed in $\mathrm{P} 2$ can be found at the end of the Supplementary information.

The microduplications identified in the affected individuals are most likely to be causative since they occurred de novo and similar microduplications are not described as CNVs in the Database of Genomic Variants. As shown in figure 2A, the microduplications overlap in an $\sim 287 \mathrm{~kb}$ proximal region (region 1) and share an $\sim 219 \mathrm{~kb}$ distal interval (region 2). Region 1 contains exons 2-4 of ATP6VOE1 (MIM 603931), the entire coding sequence of the genes SNORA74B (MIM 611331, localised within intron 3 of the ATP6VOE1 gene), BNIP1 (MIM 603291) and NKX2-5 (MIM 600584), as well as the open reading frame C5orf41. None of these genes has a known role in skeletal development, and we found no expression of these genes in the developing limb (data not shown). Mutations in NKX2-5 are associated with congenital defects of the heart such as atrial septal defect, tetralogy of Fallot and atrioventricular conduction defects. It is possible that the duplication of NKX2-5 accounts for the cardiac arrhythmia observed in P1.

Interestingly, the genomic architecture upstream of MSX2 is not fully conserved between mouse and human. As indicated by the grey bars in figure $2 \mathrm{~A}$, the first block including region 1 corresponds to mouse chromosome 17 , the second block between region 1 and region 2 to mouse chromosome 11, and the third block including region 2 as well as MSX2 is located on mouse chromosome 13 . This makes it unlikely that region 1 contains cis-regulatory elements relevant for the regulation of MSX2. In contrast, region 2 contains no RefSeq genes, but several evolutionary conserved non-coding elements (CNEs) which may constitute tissue specific enhancers for MSX2.

During skeletal development complex regulatory mechanisms are needed that dynamically control spatial and temporal expression of developmentally important genes such as secreted signalling molecules and key transcription factors. In principle, gene regulation can be mediated by regulatory promoters located immediately upstream of their target genes to direct correct gene expression. However, more complex regulation can be achieved by the so-called cis-regulatory elements that can be localised as far as $1.5 \mathrm{Mb}$ upstream or downstream of the target gene. ${ }^{12}$ Cis-regulatory elements are important mediators of gene regulation as they have the potential to activate or inhibit gene expression in distinct cell types or tissues at certain time points. In line with the particular importance of these elements, an emerging number of genetic alterations affecting regulatory elements have been identified. ${ }^{13}{ }^{14}$ Such long-range regulatory effects appear to be of particular importance for developmental genes which often show complex temporal and spatial expression patterns. A novel mutational mechanism involving the duplication of CNEs has recently been described for a number of genes including SHH (MIM 600725), IHH (MIM 600726), BMP2 (MIM 112261) and SOX9 (MIM 608160). ${ }^{14}$ These duplications are likely to exert their effect by altering gene expression of the target gene. Based on these observations, we hypothesise that the $\mathrm{CNVs}$ described here cause a CCD-like phenotype by interfering with MSX2 gene regulation. Studies addressing the regulation of $M S X 2$ gene expression focused on phylogenetically conserved cis-regulatory elements within the Msx2 promoter region. ${ }^{15-18}$ The large gene desert containing multiple CNEs $5^{\prime}$ of MSX2 is highly suggestive of extensive long range regulation. However, how these elements contribute to the spatial and temporal expression of Msx2 is unknown, and we cannot exclude that other sequences within the duplicated region 2 might have an effect on skeletal development.
MSX2 is one of three members of the Msx homeobox gene family, and Msx1 (MIM 142983) and Msx2 are believed to be functionally redundant. During embryogenesis and development, both genes are expressed at multiple sites and in a variety of tissues including the craniofacial processes and branchial arches, the tooth and limb buds, as well as the heart. ${ }^{19}$ Msx genes frequently show overlapping expression and are believed to promote lineage commitment and proliferation, but inhibit cell-type specific differentiation unless developmental patterns are established. Msx genes are highly expressed at the margins of bones in osteoblasts. Multiple studies have shown that they are, together with Runx2, Dlx5 (MIM 600028), Dlx6 (MIM 600030) and other transcription factors, involved in the regulation of osteoblast differentiation. ${ }^{20}$

It has been shown in vitro that overexpression of Msx2 inhibits osteoblastic differentiation and mineralisation of the extracellular matrix. In contrast, expression of antisense Msx2 RNA leads to decreased protein levels of Msx2 and thereby to reduced proliferation, accelerated differentiation and enhanced mineralisation. ${ }^{21}$ In an in vivo model, it has been demonstrated that overexpression of an Msx2 transgene resulted in an increased number of alkaline phosphatase-positive cells in the osteogenic front of the sagittal suture and enhanced parietal bone growth. ${ }^{22}$ Using a luciferase reporter containing the osteocalcin promoter, it has been shown that Msx2 represses the activity of Runx2 and that $D l \times 5$ counteracts this repressor activity. The authors suggest the possibility that the effects of Msx2 overexpression are mediated through the repression of Runx2 binding to its target genes. $^{23}$ Further investigation of the interactions among Dl $x 5$, $M s \times 2$ and Runx2 revealed that the inductive action of Dlx 5 on the Runx2 promoter can also be antagonised by Msx2 suggesting an inhibitory effect of Msx2 on Runx2 transcription. ${ }^{24}$

To test whether the inhibitory effect of Msx2 on mineralisation can be antagonised by Runx2 overexpression, we created two RCAS virus constructs containing Msx2 and Runx2. Chicken cells were transfected with each construct or cotransfected with both in parallel, and mineralisation was assayed using alizarin red staining. As shown in Supplementary figure S5, the inhibitory effect of Msx2 on mineralisation cannot be ameliorated by Runx2 overexpression and is thus dominant over Runx2-mediated osteoblastic induction and bone formation. These data suggest that prolonged or increased expression of MSX2 during craniofacial development may affect the spatial and temporal control of proliferation and differentiation of osteoblast precursor cells.

Haploinsufficiency of MSX2 due to loss-of-function mutations or heterozygous deletions encompassing the entire gene causes parietal foramina (MIM 168500). ${ }^{10}$ In mice inactivation of Msx2 results in multiple abnormalities including persistent calvarial defects. ${ }^{25}$ In contrast, transgenic mice overexpressing Msx2 exhibit enhanced calvarial bone growth and suture overgrowth suggesting that Msx2 dosage influences osteogenic growth in the skull, possibly by influencing the rate of cell differentiation in the sutures. ${ }^{21}{ }^{22}$ This hypothesis is supported by the observation that additional copies of the MSX2 gene are associated with craniosynostosis in humans. ${ }^{26} 27$

In some individuals, parietal foramina can be associated with hypoplasia of the clavicles. ${ }^{8}$ However, as noted by the authors, the clavicular involvement in these cases was mild and difficult to assess on physical examination whereas the clavicles were absent in the cases presented here. Furthermore, the affected individuals described here do neither show parietal foramina nor craniosynostosis, the phenotypes generally associated with MSX2 loss-of-function or gain-of-function, respectively. 


\section{Web resources}

The URLs for data presented herein are as follows: Decipher, https://decipher.sanger.ac.uk/; UCSC Genome Browser, http:// genome.ucsc.edu/; Online Mendelian Inheritance in Man (OMIM), http://www.ncbi.nlm.nih.gov/Omim; ECR browser, http:// ecrbrowser.dcode.org/; and Database of Genomic Variants (DGV), http://projects.tcag.ca/variation/.

Although the dental phenotype observed in P1 is not typical for CCD, hypodontia has been linked to mutations in several genes including MSX1. The complex synpolydactyly of the hands in P2 is reminiscent of hand malformations caused by spatiotemporal disruption of Hedgehog signalling. Recently, it has been shown that Msx1 and Msx2 expression in the limb mesenchyme modulates digit number and identity via the Shh and Bmp signalling pathways. ${ }^{28}$ The forelimb phenotype in these mice shows striking similarities to the complex synpolydactyly of the hands which we observed in P2. In addition, the hindlimbs of the Msx double conditional mutant mice showed a skeletal phenotype similar to the one observed in P2, that is, postaxial polydactyly. Although the limb phenotype in P2 primarily points to a disturbance of the Hedgehog pathway, it is notable that Hedgehog signalling also plays a role in the regulation of bone growth in the sutures. ${ }^{11}$

Based on previously described CNVs involving the MSX2 coding sequence, the effect observed here appears to be more complex than either increased or decreased MSX2 gene dosage. A similar situation has been reported for duplications involving regulatory sequences at the $I H H$ and SOX9 loci. ${ }^{11}{ }^{29}$ We conclude that the pathogenic effect of the microduplications can best be explained by a misregulation of spatiotemporal MSX2 expression patterns. Such overexpression/misexpression is likely to result in a loss of RUNX2 activity due to the antagonistic properties of MSX2, thus, mimicking RUNX2 haploinsufficiency.

Acknowledgements The authors would like to thank the families for their collaboration and contribution to this project and acknowledge the excellent technical assistance by Randi Koll and Fabienne Trotier.

Contributors CEO, EK and SM conceived the study and wrote the manuscript; JH and NF provided patient samples and clinical data; CEO, HH, SL, JG and PVL performed experiments and data analyses; EK and SS provided guidance on in situ analyses and data interpretation; all coauthors read and critically revised the manuscript and approved its final version.

Funding This work was supported by the Deutsche Forschungsgemeinschaft (DFG) grant number SFB 760, MU 880/11-01 and KL 2158/2-1.

Competing interests None.

Patient consent Obtained.

Ethics approval Ethics approval was provided by the Charité-Universitätsmedizin Berlin ethical board.

Provenance and peer review Not commissioned; externally peer reviewed.

Data sharing statement Primer sequences are available in supplementary data and on request. Detailed protocol information is available upon request.

\section{REFERENCES}

1. Mundlos S. Cleidocranial dysplasia: clinical and molecular genetics. J Med Genet 1999;36:177-82.

2. Mundlos S, Otto F, Mundlos C, Mulliken JB, Aylsworth AS, Albright S, Lindhout D, Cole WG, Henn W, Knoll JH, Owen MJ, Mertelsmann R, Zabel BU, Olsen BR. Mutations involving the transcription factor CBFA1 cause cleidocranial dysplasia. Cell 1997;89:773-9.
3. Ducy P, Zhang R, Geoffroy V, Ridall AL, Karsenty G. Osf2/Cbfa1: a transcriptional activator of osteoblast differentiation. Cell 1997;89:747-54.

4. Kim IS, Otto F, Zabel B, Mundlos S. Regulation of chondrocyte differentiation by Cbfa1. Mech Dev 1999:80:159-70.

5. Ott CE, Leschik G, Trotier F, Brueton L, Brunner HG, Brussel W, Guillen-Navarro E, Haase C, Kohlhase J, Kotzot D, Lane A, Lee-Kirsch MA, Morlot S, Simon ME, Steichen-Gersdorf E, Tegay DH, Peters H, Mundlos S, Klopocki E. Deletions of the RUNX2 gene are present in about $10 \%$ of individuals with cleidocranial dysplasia. Hum Mutat 2010;31:E1587-93.

6. Khan A, Hyde RK, Dutra A, Mohide P, Liu P. Core binding factor beta (CBFB) haploinsufficiency due to an interstitial deletion at 16q21q22 resulting in delayed cranial ossification, cleft palate, congenital heart anomalies, and feeding difficulties but favorable outcome. Am J Med Genet A 2006;140:2349-54.

7. Kundu M, Javed A, Jeon JP, Horner A, Shum L, Eckhaus M, Muenke M, Lian JB, Yang Y, Nuckolls GH, Stein GS, Liu PP. Cbfbeta interacts with Runx2 and has a critical role in bone development. Nat Genet 2002;32:639-44.

8. Garcia-Miñaur S, Mavrogiannis LA, Rannan-Eliya SV, Hendry MA, Liston WA, Porteous ME, Wilkie A0. Parietal foramina with cleidocranial dysplasia is caused by mutation in MSX2. Eur J Hum Genet 2003;11:892-5.

9. Mavrogiannis LA, Taylor IB, Davies SJ, Ramos FJ, Olivares JL, Wilkie AO. Enlarged parietal foramina caused by mutations in the homeobox genes ALX4 and MSX2: from genotype to phenotype. Eur J Hum Genet 2006;14:151-8.

10. Wilkie A0, Tang Z, Elanko N, Walsh S, Twigg SR, Hurst JA, Wall SA, Chrzanowska $\mathrm{KH}$, Maxson RE Jr. Functional haploinsufficiency of the human homeobox gene MSX2 causes defects in skull ossification. Nat Genet 2000;24:387-90.

11. Klopocki E, Lohan S, Brancati F, Koll R, Brehm A, Seemann P, Dathe K, Stricker S, Hecht J, Bosse K, Betz RC, Garaci FG, Dallapiccola B, Jain M, Muenke M, Ng VC, Chan W, Chan D, Mundlos S. Copy-number variations involving the $\mathrm{IHH}$ locus are associated with syndactyly and craniosynostosis. Am J Hum Genet 2011;88:70-5

12. Howard ML, Davidson EH. cis-Regulatory control circuits in development. Dev Biol 2004:271:109-18.

13. Kleinjan DA, Lettice LA. Long-range gene control and genetic disease. Adv Genet 2008:61:339-88.

14. Klopocki E, Mundlos S. Copy-number variations, noncoding sequences, and human phenotypes. Annu Rev Genomics Hum Genet 2011;12:53-72.

15. Brugger SM, Merrill AE, Torres-Vazquez J, Wu N, Ting MC, Cho JY, Dobias SL, Yi SE, Lyons K, Bell JR, Arora K, Warrior R, Maxson R. A phylogenetically conserved cisregulatory module in the Msx2 promoter is sufficient for BMP-dependent transcription in murine and Drosophila embryos. Development 2004:131:5153-65.

16. Cheng HC, Wang CK, Upholt WB. Transcriptional regulation of Msx2 in the AERs of developing limbs is dependent on multiple closely spaced regulatory elements. Dev Biol 2004;270:513-24.

17. Hussein SM, Duff EK, Sirard C. Smad4 and beta-catenin co-activators functionally interact with lymphoid-enhancing factor to regulate graded expression of Msx2. J Biol Chem 2003;278:48805-14.

18. Tan DP, Nonaka K, Nuckolls GH, Liu YH, Maxson RE, Slavkin HC, Shum L. YY1 activates Msx2 gene independent of bone morphogenetic protein signaling. Nucleic Acids Res 2002;30:1213-23.

19. Davidson $\mathbf{D}$. The function and evolution of Msx genes: pointers and paradoxes. Trends Genet 1995:11:405-11.

20. Komori T. Regulation of osteoblast differentiation by transcription factors. J Cell Biochem 2006;99:1233-9.

21. Dodig M, Tadic T, Kronenberg MS, Dacic S, Liu YH, Maxson R, Rowe DW, Lichtle AC. Ectopic Msx2 overexpression inhibits and Msx2 antisense stimulates calvarial osteoblast differentiation. Dev Biol 1999;209:298-307.

22. Liu YH, Tang Z, Kundu RK, Wu L, Luo W, Zhu D, Sangiorgi F, Snead ML, Maxson RE. Msx2 gene dosage influences the number of proliferative osteogenic cells in growth centers of the developing murine skull: a possible mechanism for MSX2-mediated craniosynostosis in humans. Dev Biol 1999;205:260-74.

23. Shirakabe K, Terasawa K, Miyama K, Shibuya H, Nishida E. Regulation of the activity of the transcription factor Runx2 by two homeobox proteins, Msx2 and Dlx5. Genes Cells 2001;6:851-6.

24. Lee MH, Kim YJ, Yoon WJ, Kim JI, Kim BG, Hwang YS, Wozney JM, Chi XZ, Bae SC, Choi KY, Cho JY, Choi JY, Ryoo HM. Dlx5 specifically regulates Runx2 type II expression by binding to homeodomain-response elements in the Runx2 distal promoter. J Biol Chem 2005;280:35579-87.

25. Satokata I, Ma L, Ohshima H, Bei M, Woo I, Nishizawa K, Maeda T, Takano Y, Uchiyama M, Heaney S, Peters H, Tang Z, Maxson R, Maas R. Msx2 deficiency in mice causes pleiotropic defects in bone growth and ectodermal organ formation. Nat Genet 2000;24:391-5.

26. Bernardini L, Castori M, Capalbo A, Mokini V, Mingarelli R, Simi P, Bertuccelli A, Novelli A, Dallapiccola B. Syndromic craniosynostosis due to complex chromosome 5 rearrangement and MSX2 gene triplication. Am J Med Genet A 2007;143A:2937-43.

27. Shiihara T, Kato M, Kimura T, Hayasaka K, Yamamori S, Ogata T. Craniosynostosis with extra copy of MSX2 in a patient with partial 5q-trisomy. Am J Med Genet A 2004;128A:214-16.

28. Bensoussan-Trigano V, Lallemand $Y$, Saint Cloment $C$, Robert B. Msx 1 and Msx2 in limb mesenchyme modulate digit number and identity. Dev Dyn 2011:240:1190-202.

29. Kurth I, Klopocki E, Stricker S, van Oosterwijk J, Vanek S, Altmann J, Santos HG, van Harssel JJ, de Ravel T, Wikie A0, Gal A, Mundlos S. Duplications of noncoding elements $5^{\prime}$ of SOX9 are associated with brachydactyly-anonychia. Nat Genet 2009;41:862-3. 


\section{Microduplications upstream of MSX2 are associated with a phenocopy of cleidocranial dysplasia}

Claus Eric Ott, Hendrikje Hein, Silke Lohan, et al.

J Med Genet 2012 49: 437-441 originally published online June 20, 2012

doi: 10.1136/jmedgenet-2012-100825

Updated information and services can be found at:

http://jmg.bmj.com/content/49/7/437.full.html

These include:

\section{Data Supplement "Supplementary Data"}

http:/jmg.bmj.com/content/suppl/2012/07/11/jmedgenet-2012-100825.DC1.html

References This article cites 29 articles, 5 of which can be accessed free at:

http://jmg.bmj.com/content/49/7/437.full.html\#ref-list-1

Article cited in:

http://jmg.bmj.com/content/49/7/437.full.html\#related-urls

Email alerting Receive free email alerts when new articles cite this article. Sign up in service the box at the top right corner of the online article.

Topic Articles on similar topics can be found in the following collections

Collections
Calcium and bone (278 articles)
Genetic screening / counselling (751 articles)
Immunology (including allergy) (507 articles)
Molecular genetics (1111 articles)

Notes

To request permissions go to:

http://group.bmj.com/group/rights-licensing/permissions

To order reprints go to:

http://journals.bmj.com/cgi/reprintform

To subscribe to BMJ go to:

http://group.bmj.com/subscribe/ 